
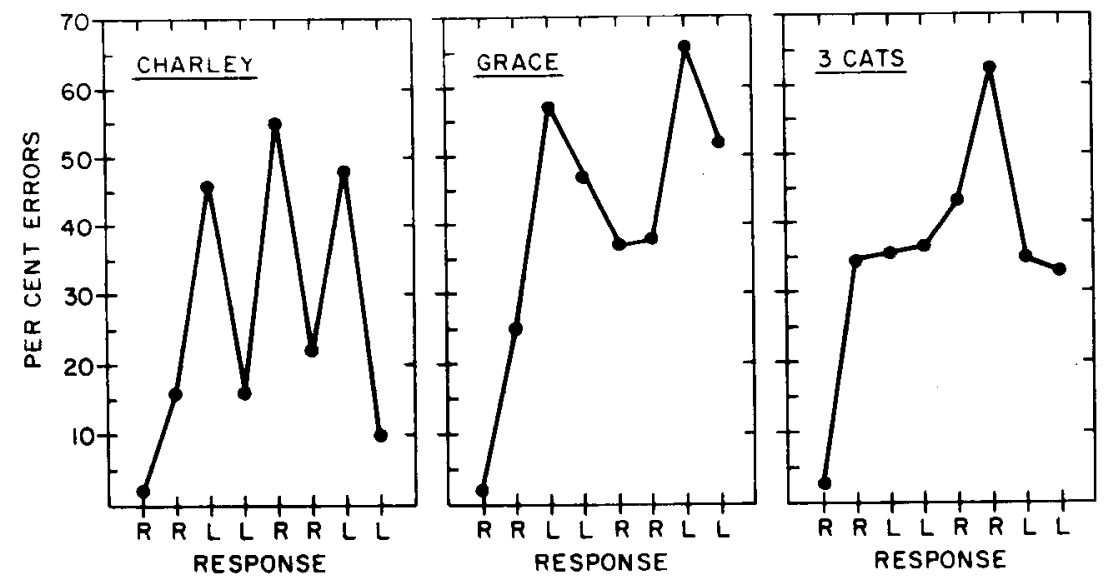

None of the experimental Ss approached solution of the double-alternation problem. The mean percentage of correct responses on the last 25 days of training on double alternation was 66 ; individual scores ranged from $60 \%$ to $74 \%$ correct responses. Analysis of the cats' performances revealed, however, that the five Ss manifested three different sorts of response strategies on double alternation. These are illustrated in Fig. 2 which shows the percentage of errors made on each response in the double-alternation sequence over the last 100 sequences (25 days). Cat Charley manifested a strong tendency to perseverate after reinforcement and to shift after nonreinforcement. Grace developed a significant right-position bias. The remaining three cats apparently learned that the right position was rewarded at the start of each sequence and little more than this since they responded at or near chance on later trials in the sequence. Charley, the cat that developed a "win-stay, lose-shift with respect to position" strategy, was exceptional in his retest performance in discrimination learning; he made more than twice as many errors on the problems that followed double-alternation training than he had before the interpolated training (668 errors on Problems 97-128 vs 328 on Problems 65-96).

\section{DISCUSSION}

The group results indicate that prolonged and unsuccessful training on an insoluble problem does not interfere with the retention of discrimination-learning sets by cats. It is clear that prolonged training on an insoluble task is neither a necessary nor a sufficient condition for disruption of visual-discrimination learning sets in cats.

One cat, Charley, developed a relatively stable stereotyped pattern of responding on double alternation. This $S$ was the only animal which was markedly deficient in retest performance on visual-discrimination problems, suggesting that the acquisition of specific sequential patterns of response that conflict with the responses essential for efficient learning-set performance is a necessary condition for impairment of the retention of learning sets in cats. The fact that a second cat, Grace, developed a strong position bias but was not subsequently impaired in learning-set performance implies that the development of response habits incompatible with efficient visual discrimination is not sufficient to impair retention of visual discrimination-learning sets. This interpretation makes it possible to resolve the otherwise puzzling paradox posed by Warren \& Sinha's (1959) observation that interpolated training on a soluble double-altemation problem depresses the retention of a visual discrimination learning set by rhesus monkeys. The monkeys, like the exceptional cat Charley, learned to make stereotyped sequences of positional responses in training on double altemation and thus were subject to conflict between

\section{RAY OVER, Dalhousie University, Halifax, Nova Scotia, Canada}

Four pigeons were trained to discriminate between mirror-image oblique lines and between horizontal and vertical lines. On each trial, a response on the center key displayed one of the discriminative stimuli, and reinforcement was gained by a response on the appropriate side key. Choice reaction times did not differ for the two sets of
Fig. 2. Intrasequential distribution of errors on eight-response double-alternation sequences.

antagonistic response tendencies when retested on visual discriminations.

It should be noted that the results obtained from the control group of cats in this experiment indicate that the retention of discrimination-learning sets is as little affected by long interruptions in testing as seems to be the case with monkeys (Miles, 1965).

\section{REFERENCES}

DALRYMPLE, S. D., \& STRETCH, R. Disruption of a position-reversal learning set in the rat. Quarterly Journal of Experimental Psychology, $1966,18,250-253$.

HARLOW, H. F. The formation of learning sets. Psychological Review, 1949, 56, 51-65.

MILES, R. C. Discrimination-learning sets. In A. M. Schrier, H. F. Harlow, and F. Stollnitz (Eds.), Behavior of nonhuman primates: Modern research trends. Vol. 1. New York: Academic Press, 1965. Pp. 51-95.

RUMBAUGH, D. M., \& PRIM, M. M. Temporary interference of insolvable discrimination reversal training upon learning set in the squirrel monkey. Journal of Comparative \& Physiological Psychology, 1964, 57, 302-304. STEWART, C. N., \& WARREN, J.M. The behavior of cats on the double-alternation problem. Journal of Comparative \& Physiological Psychology, 1957, 50, 26-28.

WARREN, J. M., \& BARON, A. The formation of learning sets by cats. Journal of Comparative \& Physiological Psychology, 1956, 49, 227-231.

WARREN, J. M., \& SINHA, M. M. Interactions between learning sets in monkeys. Journal of Genetic Psychology, 1959, 95, 19-25.

$$
\text { NOTE }
$$

1 . This research was supported by Grant MH-04726 from the National Institute of Mental Health, United States Public Health Service.

\title{
Reaction time analysis of discrimination of direction of line by the pigeon ${ }^{1}$
}

figures These results are consistent with trials-to-criterion measures of the discrimination of direction of line by the pigeon.

Shape discrimination by animals is studied by presenting two figures, either simultaneously or successively, and rewarding responses specific to one shape but not to the other. An animal's ability to 
distinguish two figures is generally specified in terms of the number of trials required for a given level of response accuracy to be attained. Discrimination of direction of line has received considerable attention since the demonstration by Sutherland (1957) that the octopus can distinguish horizontal and vertical lines but confuses mirror-image oblique lines. It has subsequently been shown that several species, including the pigeon (Zeigler \& Schmerler, 1965), discriminate mirror-image oblique lines as readily as horizontal and vertical lines. Bimodal angularity generalization gradients are obtained, however, after pigeons have been reinforced for pecking at a single oblique line; peaks of responding occur at both the training stimulus and its mirror-image (Thomas, Klipec, \& Lyons, 1966). This demonstration that pigeons, in some respects, confuse left-right reversed figures suggests that trial-to-criterion or error-rate measures may not provide the most suitable index of the discriminability of different sets of shapes. Results obtained with adult human Ss (Butler, 1964; Sekuler \& Houlihan, 1968) bear on this issue; choice reaction times are longer when left-right mirror-image shapes are being judged even though these figures are discriminated with as few errors as up-down reversed shapes.

The present experiment examines the ability of pigeons to distinguish different directions of line following extensive training. It is asked whether choice reaction times are longer for discrimination of mirror-image oblique lines than for horizontal and vertical lines.

\section{METHOD}

Four adult White Carneaux pigeons were maintained at $80 \%$ of their free-feeding weights. The animals were experimentally naive at the beginning of testing.

The apparatus consisted of a seven-sided metal panel, which approximated a semicircle of 12 -in. diam and was located within a sound attenuating compartment. Three transparent response keys of 1-in. diam were mounted on the panel, and a multiple-stimulus projector was fixed behind each key. The middle key was 10.5 in. from the floor and 6 in. above the food magazine. The centers of adjacent keys were separated by $2.5 \mathrm{in}$. There was no houselight in the chamber, but the food magazine was illuminated when it operated. Standard electromechanical programming and recording equipment were used. Reaction times were measured in the following manner. Presentation of the discriminative stimulus on the middle key initiated a hold circuit operating an electronic timer which sent out pulses to a counter. The animal's response on a side key terminated the hold circuit. The nominal interpulse interval of the timer was $0.1 \mathrm{sec}$; the actual interval was $0.126 \mathrm{sec}$. Reaction times were recorded manually.

Each pigeon was initially shaped to peck with the side keys dark and the middle key green; responding on the middle key resulted in $3 \mathrm{sec}$ access to the food magazine. A discrete-trial procedure was used in the discrimination training given following shaping. At the start of each trial, the middle key was green and the side keys were dark. A single response to the middle key turned the side keys white and displayed three parallel black lines on a white background on the middle key. The four stimuli used formed part of Grason-Stadler Pattern 165, and displayed lines tilted 0,45 , 90 , or $135 \mathrm{deg}$ from the vertical. Two pigeons we re initially trained to discriminate the mirror-image oblique lines (one was trained to respond on the left key when the 45-deg lines were displayed on the middle key and to respond to the right key when the 135-deg lines were shown; the other was tested with the reverse arrangement), and two animals were initially tested on the horizontal-vertical discrimination. A response to the correct side key was followed by $3 \mathrm{sec}$ access to food; 2 sec later, the next trial commenced with display of the green stimulus on the middle key. A correction procedure was used following an incorrect response; the three keys were darkened for $20 \mathrm{sec}$, and the discriminative stimulus was then presented again. A single session of 64 trials was given daily, with the stimuli presented in chance sequences (Fellows, 1967). Reaction times were first measured when an animal had been correct on 58 or more trials on each of four consecutive sessions. Each animal was transferred to the second set of shapes after measures had been obtained with the training shapes over three sessions. In the last stage, reaction times were measured with the four discriminative stimuli presented 16 times in random order in each session, and with reinforcement contingencies similar to those which prevailed when the two pairs of shapes had been displayed separately. This arrangement is referred to later as the mixed-stimulus condition.

\section{RESULTS}

The two pigeons initially trained to discriminate mirror-image oblique lines reached $90 \%$ accuracy within a session after 9 and 13 sessions, respectively; the animals trained with horizontal and vertical lines required 5 and 12 sessions. Median reaction times are shown in Table 1 for the four pigeons and two sets of figures (45 vs $135 \mathrm{deg}$ and 0 vs $90 \mathrm{deg}$, with the pairs presented separately and under mixed-stimulus conditions). Reaction times for accurate discrimination of mirror-image oblique lines do not differ from values
Table 1

Median Reaction Times in Seconds

\begin{tabular}{|c|c|c|c|c|}
\hline \multirow[b]{2}{*}{ Ss } & \multicolumn{2}{|c|}{ Separate Pairs } & \multicolumn{2}{|c|}{ Mixed Presentation } \\
\hline & $\begin{array}{c}0 \text { deg vs } \\
90 \mathrm{deg}\end{array}$ & $\begin{array}{c}45 \text { deg vs } \\
135 \text { deg }\end{array}$ & $\begin{array}{c}0 \text { deg vs } \\
90 \mathrm{deg}\end{array}$ & $\begin{array}{c}45 \text { deg vs } \\
135 \text { deg }\end{array}$ \\
\hline$S-5$ & .63 & .63 & .73 & .70 \\
\hline$S-6$ & .83 & .86 & .83 & .88 \\
\hline$S-8$ & .73 & .71 & .83 & .79 \\
\hline$S-10$ & .78 & .82 & .76 & .71 \\
\hline
\end{tabular}

obtained when horizontal and vertical lines are judged. The low response latencies (medians less than $1 \mathrm{sec}$ ) obtained with pigeons in the present experiment suggest that decision processes have not been obscured by a considerable response component in the measures.

\section{DISCUSSION}

Behavioral measures of shape discrimination have often been used (e.g., Deutsch, 1962; Sutherland, 1963) to develop hypotheses about operations by which the visual system analyzes and classifies information about the spatial properties of figures. In these theories, it is assumed that the difficulty animals have in distinguishing shapes provides an index of the degree to which the figures generate similar signals in the visual system. Response-accuracy measures are typically used in establishing the discriminability of shapes. In the present experiment, it has been shown that reaction-time measures of the discrimination of direction of line by the pigeon parallel the response-accuracy measures reported by Zeigler \& Schmerler (1965). Unlike human Ss (Butler, 1964; Sekuler \& Houlihan, 1968), pigeons distinguish left-right reversed figures as readily as horizontal and vertical lines.

\section{REFERENCES}

BUTLER, J. Visual discrimination of shape by humans. Quarterly Journal of Experimental Psychology, 1964, 16, 272-276.

DEUTSCH, J. A. A system for shape recognition. Psychological Review, 1962, 69, 492-500.

FELLOWS, B. J. Chance stimulus sequences for discrimination tasks. Psychological Bulletin, $1967,67,87,92$.

SEKULER, R. W. \& HOULIHAN, K. Discrimination of mirror-images: Choice time analysis of human adult performance. Quarterly Journal of Experimental Psychology, 1968, 20, 204-207.

SUTHERLAND, N. S. Visual discrimination or orientation by octopus. British Journal of Psychology, 1957, 48, 55-71.

SUTHERLAND, N. S. Shape discrimination and receptive fields. Nature, 1963, 197, 118-122.

THOMAS, D. R., KLIPEC, W., \& LYONS, J. Investigations of a mirror-image transfer effect in pigeons. Joumal of the Experimental Analysis of Behavior, 1966, 9, 567-571.

ZEIGLER, H. P., \& SCHMERLER, S. Visual discrimination of orientation by pigeons. Animal Behavior, 1965, 13,475-477. NOTE

1. This research was supported by Grant APA-319 from the National Research Council of Canada. 